\title{
EMDR y psicosis: \\ Pautas de conceptualización y tratamiento
}

\author{
David P. G. Van den Berg \\ Instituto Psiquiátrico Parnassia, La Haya, Holanda \\ Berber M. Van der Vleugel \\ Servicio Comunitario de Salud Mental GGZ Noord-Holland Noord, Alkmaar, Holanda \\ Anton B. P. Staring \\ Instituto Psiquiátrico Altrecht, Utrecht, Holanda \\ Paul A. J. De Bont \\ Organización de Salud Mental GGZ Oost Brabant Land van Cuijk en Noord Limburg, Boxmeer, Holanda. \\ Ad De Jongh \\ Centro Académico de Odontología de Amsterdam (ACTA) \\ Universidad de Amsterdam y Universidad VU \\ Escuela de Ciencias de la Salud de Amsterdam, Universidad de Salford, Manchester, Inglaterra
}

\begin{abstract}
Un porcentaje significativo de clientes con psicosis ha experimentado trauma infantil y sufre de trastorno de estrés postraumático comórbido. Las investigaciones indican que la exposición a eventos angustiosos los primeros años de vida juega un papel importante en la aparición y persistencia de síntomas psicóticos, ya sea directa o indirectamente. El Enfoque de Dos Métodos para la conceptualización de EMDR y los recientes descubrimientos sobre el reprocesamiento de las imágenes relacionadas con la psicosis encajan con los modelos cognitivos actuales de psicosis. En este artículo se presentan una serie de pautas preliminares para conceptualizar el tratamiento EMDR de la psicosis, basadas tanto en la teoría como en la experiencia clínica, y se ilustran con ejemplos de casos. Se describen diversos obstáculos y estrategias de tratamiento para el uso de EMDR en la psicosis. El EMDR para la psicosis puede combinarse muy bien con otras intervenciones estándar, tales como la medicación psicotrópica y la terapia cognitivo-conductual.
\end{abstract}

Palabras clave: trauma; psicosis; EMDR; delirios; alucinaciones verbales auditivas; TEPT.

$\mathbf{E}$ studios recientes revelan de forma inequívoca que la mayoría de las personas con psicosis han sufrido traumas en la infancia y que estas experiencias adversas pueden influir causalmente en el desarrollo y la persistencia de los síntomas psicóticos (Matheson, Pastor, Pinchbeck, Laurens y Carr, 2013; Read, Van Os, Morrison y Ross, 2005; Varese at al., 2012). Por otra parte, las relaciones entre el trauma y la psicosis se han vuelto más claras (Morrison, Frame y Larkin, 2003). Esto sugiere que los tratamientos centrados en el trauma pueden ser una incorporación importante al tratamiento de la psicosis (Callcott, Standart y Turkington, 2004).

Una parte importante de los clientes con psicosis sufre de trastorno de estrés postraumático comórbido (TEPT). Las tasas de prevalencia estimadas para el TEPT actual en la psicosis varían entre un $10 \mathrm{y}$ un 30\% (Achim et al., 2011; Buckley, Miller, Lehrer

This article originally appeared as Van den Berg et al. (2013). EMDR in Psychosis: Guidelines for Conceptualization and Treatment. Journal of EMDR Practice and Research, 7(4): 208-224. Translated by Miriam Ramos Morrison. 
y Castle, 2009). Otros estudios sobre el TEPT en la psicosis encuentran tasas de prevalencia más altas, pero la mayoría de estos estudios tienen limitaciones importantes debido al uso de auto-informes o de muestras pequeñas. Además, algunos estudios no indican si se ha estudiado el TEPT del presente o el de la vida entera.

Muchos terapeutas son reacios a utilizar la terapia EMDR u otras terapias centradas en el trauma, tales como la exposición prolongada (EP), con clientes que sufren de psicosis y TEPT comórbido. En consecuencia, la psicosis ha sido un criterio de exclusión en casi todos los estudios sobre TEPT (Spinazzola, Blaustein y Van der Kolk, 2005). Aunque la evidencia empírica de la eficacia del tratamiento del trauma en la psicosis es escasa, la experiencia clínica y los estudios exploratorios son prometedores (De Bont, Van Minnen y De Jongh, 2013; Frueh et al., 2009; Van den Berg y Van der Gaag, 2012). Estos estudios cuestionan las creencias tradicionales de que la psicosis debería ser una contraindicación para el tratamiento del TEPT comórbido en personas con psicosis.

Dos de estos estudios aplicaron con éxito y de manera segura la terapia EMDR. Las tasas de abandono fueron bajas y se encontró que el tratamiento del TEPT estaba asociado con una mejoría significativa de la depresión, la ansiedad, la autoestima, e incluso en uno de estos estudios parecía haber disminuido la cantidad de alucinaciones (Van den Berg y Van der Gaag, 2012). Claramente, es necesario continuar investigando. En el momento de escribir este texto, se está realizando un ensayo clínico aleatorizado multi-céntrico, que investiga la seguridad y la eficacia de la terapia EMDR y la exposición prolongada para tratar a clientes con psicosis y TEPT comórbido (De Bont, Van den Berg, et al., 2013). Cabe destacar que, en estos estudios, no se utilizaron procedimientos de estabilización previos a la aplicación del procedimiento EMDR.

Hasta la fecha, sólo un estudio publicado ha utilizado EMDR para hacer blanco específicamente sobre los síntomas psicóticos en lugar del TEPT comórbido. En este ensayo clínico aleatorizado, se utilizó el EMDR para hacer blanco sobre los síntomas psicóticos en un ámbito hospitalario ( $\mathrm{N}=45$; Kim et al., 2010). Se compararon los efectos de tres sesiones de EMDR con un entrenamiento en relajación. No se encontraron efectos o diferencias significativas. Probablemente, esta falta de efecto se deba al hecho de que todos los clientes habían sido ingresados por un episodio psicótico agudo y, en consecuencia, habían recibido un tratamiento amplio (incluyendo medicamentos). Esto podría haber ocultado el resto de los efectos del tratamiento. Tal vez lo más importante a tener en cuenta es que el método EMDR no causó ningún tipo de problema.

En este artículo se describen la conceptualización y la aplicación del EMDR en el tratamiento de los síntomas psicóticos y las imágenes relacionadas con la psicosis, utilizando el enfoque de dos métodos. La atención se centra principalmente en los delirios y las alucinaciones auditivas verbales (es decir, voces). Este enfoque está ilustrado con varios ejemplos de casos. Por otra parte, se presta atención a los obstáculos y las complicaciones con los que nos podemos encontrar al aplicar la terapia EMDR a clientes con psicosis. Se presentan estrategias de tratamiento para hacer frente a estos obstáculos. Debido a la naturaleza compleja de la mayoría de las psicosis, se sugiere que el EMDR se combine con otras estrategias terapéuticas, incluyendo el uso de intervenciones cognitivo-conductuales. Cabe señalar que, por el momento, no existe una base científica para el uso de EMDR en la psicosis. Por consiguiente, este artículo se basa en la experiencia clínica de los autores.

\section{Hablando del trauma en la psicosis}

Por lo general, los clientes con enfermedades mentales graves (EMG) tienen ganas de hablar de sus experiencias traumáticas (Lothian y Read, 2002). Por el contrario, los terapeutas parecen temer que, inevitablemente, esto dará lugar a eventos adversos (Read, Hammersley y Rudegeair, 2007). Esta "hipótesis del daño" está, sin embargo, en contradicción con estudios de intervención (de Bont, Van Minnen, et al., 2013; Frueh et al., 2009; Mueser et al., 2008; Van den Berg y Van der Gaag, 2012). Además, dicho supuesto no encontró apoyo en un estudio que vio que los clientes con EMG lidian bien con las entrevistas sobre el trauma (Grubaugh, Tuerk, Egede y Frueh, 2012).

El hablar sobre traumas y experiencias disfuncionales de interacción con padres, compañeros y otras personas puede ser inquietante para los clientes, pero esto no se observa exclusivamente en aquellos que sufren de psicosis. Por ello, el terapeuta debe ser empático, pero a la vez ha de estar orientado hacia los objetivos. Una analogía útil es la de un médico de primeros auxilios que limpia y cose una herida desagradable, no sólo de modo empático sino también orientado a la tarea, en lugar de proyectar miedo a la sangre y al dolor. El sufrimiento emocional que acompaña al tratamiento de los traumas es generalmente temporal. La carga de ir por la vida con un TEPT sin tratar es, a menudo, mucho más preocupante, ya que se traduce en el refuerzo de ciclos negativos entre los síntomas del TEPT y la psicosis (Mueser, Rosenberg, 
Goodman y Trumbetta, 2002). Consideremos los siguientes motivos:

Por desgracia, has experimentado algunas cosas realmente terribles. Afortunadamente, estas cosas están ahora en el pasado. Sin embargo, todavía experimentas recuerdos intrusivos de ellas. Como sabes, los recuerdos pueden ser muy inquietantes, pero realmente no pueden hacerte daño [dar un ejemplo: tu padre realmente te hizo daño físicamente; pero el recuerdo de tu padre no]. En el tratamiento, vamos a trabajar con tus peores recuerdos. Esto te ayudará a experimentar que tienes la fuerza y la resistencia necesarias para hacerles frente. Estoy seguro de que tú también tendrás éxito.

Muchos clientes con EMG llevan consigo planes de afrontamiento o planes de emergencia. Para facilitar la estabilidad y la seguridad, estos planes pueden ser actualizados y adaptados antes de que comience el tratamiento con EMDR. Por otra parte, los autores del presente estudio destacan la importancia de tener experiencia con clientes psicóticos antes de utilizar el EMDR con esta población. Aunque se defiende el uso del procedimiento estándar de EMDR, se considera importante estar familiarizado con la complejidad de la mayoría de las psicosis, la presencia de trastornos comórbidos y el contexto de trabajo dentro de un equipo multidisciplinario de salud mental.

\section{Indicaciones para el uso de EMDR en la psicosis}

En primer lugar, en la psicosis, el EMDR está indicado para el TEPT comórbido. El TEPT es un trastorno comórbido de alta prevalencia en la psicosis (Achim et al., 2011; Buckley et al., 2009). El TEPT no tratado influye negativamente en los síntomas de psicosis y en el pronóstico de los clientes (Mueser et al., 2002).

En segundo lugar, el EMDR puede ser utilizado con los síntomas psicóticos que estén directamente relacionados con acontecimientos vitales (traumáticos) anteriores. Por ejemplo, la paranoia que comenzó inmediatamente después de una experiencia traumática (por ejemplo, un atraco) o las voces que están claramente relacionadas con el trauma (Hardy et al., 2005; Morrison et al., 2003).

En tercer lugar, el uso de EMDR está indicado cuando los acontecimientos de la vida influyen indirectamente en la psicosis a través de creencias centrales y supuestos intermedios sobre uno mismo, los demás y el mundo. Por ejemplo, las experiencias de acoso en la infancia pueden dar lugar a expectativas negativas de los demás, lo que finalmente se traduce en delirios paranoides (Fisher et al., 2012). Del mismo modo, se ha demostrado que la baja autoestima influye intensamente en las reacciones a las voces insultantes (Paulik, 2012). Las investigaciones indican que estos supuestos forman un importante vínculo cognitivo entre el trauma y la psicosis (Fowler et al., 2006; Gracie et al., 2007).

Por último, el EMDR puede utilizarse para reprocesar expectativas imaginadas poco realistas, atemorizantes y negativas o imágenes negativas relacionadas con la psicosis. La mayoría de los clientes con psicosis refieren este tipo de imágenes intrusivas (Lockett et al., 2012; Morrison et al., 2002; Schulze, Freeman, Green y Kuipers, 2013). Los resultados preliminares muestran que trabajar con las imágenes podría reducir los síntomas psicóticos (Morrison, 2004).

La Tabla 1 muestra las posibles indicaciones y conceptualizaciones para la aplicación de EMDR en la psicosis usando el enfoque de dos métodos (De Jongh, Ten Broeke y Meijer, 2010). El terapeuta puede seguir el protocolo estándar de EMDR, sin embargo, debe

TABLA 1. Indicaciones y conceptualización para el EMDR en la psicosis

\begin{tabular}{lcc}
\hline Objetivo & Blanco / Diana & Método \\
\hline $\begin{array}{l}\text { Reducción de síntomas del } \\
\text { TEPT comórbido }\end{array}$ & $\begin{array}{c}\text { Recuerdos de eventos vitales } \\
\text { traumáticos que se reviven con } \\
\text { frecuencia }\end{array}$ & Protocolo estándar de EMDR \\
$\begin{array}{l}\text { Reducción de síntomas } \\
\text { psicóticos }\end{array}$ & Eecuerdos de eventos vitales directa- \\
& $\begin{array}{c}\text { Recuerdo conectados con la psicosis } \\
\text { rectamente conectados con la } \\
\text { psicosis }\end{array}$ & Enfoque del segundo método de EMDR \\
& $\begin{array}{l}\text { Imágenes relevantes relacionadas con } \\
\text { la psicosis }\end{array}$ & EMDR sobre los "flash-forwards” o imá- \\
\end{tabular}

Nota. TEPT: Trastorno de Estrés Postraumático; EMDR: siglas en inglés de Desensibilización y Reprocesamiento por Movimientos Oculares (Eye Movement Desensitization and Reprocessing). 
tener en cuenta ciertos obstáculos específicos que posiblemente puedan aparecer en los clientes psicóticos. Éstos se comentarán más adelante en este artículo, junto con varias estrategias de tratamiento para hacerles frente.

\section{EMDR, el enfoque de dos métodos y las imágenes}

La experiencia adquirida en la aplicación de EMDR en los últimos años ha demostrado que es posible extender este tratamiento a una amplia variedad de síntomas psicológicos. En consecuencia, cuando un terapeuta en el contexto de su tratamiento decide usar terapia EMDR, el tratamiento se centrará en volver a dar forma a los recuerdos que sustentan los síntomas que sufre el cliente. Por tanto, antes de comenzar el tratamiento, el terapeuta tendrá que elaborar una hipótesis coherente sobre la relación entre los problemas presentados, además del TEPT en sí, así como un listado de recuerdos diana significativos para tratarlos con EMDR.

El enfoque de dos métodos es un enfoque integral destinado a ayudar a los terapeutas a conceptualizar sus casos, haciendo, por tanto, que sea posible formular hipótesis sobre qué blancos son esenciales para aliviar los síntomas. En otras palabras, se trata de un procedimiento estructurado que se realiza antes del EMDR para seleccionar qué recuerdos vamos a procesar. Después de que se hayan identificado las dianas utilizando este método, se utiliza el protocolo estándar de EMDR para reprocesar los recuerdos (De Jongh et al., 2010). El enfoque de dos métodos es considerado como una expansión del modo tradicional de conceptualización de EMDR mediante preguntas (Shapiro, 1995, 2001). Este modelo de conceptualización del caso tiene dos componentes (ver De Jongh et al., 2010 para una descripción detallada).

El primer método (véase la Figura 1) se utiliza con los síntomas, por lo que los recuerdos de los acontecimientos etiológicos y agravantes pueden ser identificados y formulados en una línea de tiempo de manera significativa. Está dirigido principalmente a la conceptualización de EMDR en el tratamiento de los trastornos del Eje I del Manual diagnóstico y estadístico de los trastornos mentales, cuarta edición, texto revisado (DSM-IV-TR). El punto de partida es el síntoma diana o blanco (cluster). Se identifican los eventos etiológicos y los agravantes posteriores. Las preguntas para aclarar esto son las siguientes: "Desde tu punto de vista, qué hecho o hechos es/son responsable de tus problemas actuales o han podido empeorarlos?" o "¿qué acontecimientos han dado lugar a tus síntomas?" Trazamos entonces una línea de tiempo con el curso de los problemas. Se identifican los recuerdos diana más importantes y se puntúan en una jerarquía. Posteriormente, se aplica el protocolo estándar.

El segundo método se utiliza para identificar los recuerdos que subyacen a las creencias nucleares disfuncionales o suposiciones intermedias del cliente. Este método se utiliza principalmente con psicopatología compleja en la que los supuestos disfuncionales subyacentes tienen una influencia importante. El punto de partida en el segundo método son las creencias centrales negativas disfuncionales que están conectadas con los problemas del cliente. Se identifican las imágenes diana de las experiencias que han llevado a la formación de estas creencias negativas sobre uno mismo, los demás y el mundo (la llamada "evidencia"). Aquí se pueden hacer las siguientes preguntas: "¿Qué te hizo (empezar a) creer que eres un (a) _ [creencia nuclear]?”; "¿qué te 'enseñó' que eres (a) __ [creencia nuclear]?”; “¿qué experiencias tempranas 'prueban', por así decirlo, hoy en día que eres (a) _ [creencia nuclear]?"; o "piensa en una situación más reciente que te indique claramente que eres (a) _ [creencia nuclear]" Estas evidencias son posteriormente valoradas jerárquicamente (de "pruebas" fuertes a débiles) y se reprocesan con el protocolo estándar de EMDR para obtener la desactivación de los esquemas negativos o una disminución de su credibilidad.

Además, hay un tercer modo de conceptualización de casos dentro del EMDR. Está dirigido a expectativas poco realistas y atemorizantes o imágenes negativas asociadas con la psicopatología. Esto encaja con la creciente evidencia que muestra que las imágenes son un factor importante en la aparición y persistencia de los trastornos emocionales (Beck, 1970; Hackmann, Surawy y Clark, 1998). Originalmente, el EMDR está dirigido a imágenes negativas de acontecimientos pasados (es decir, recuerdos o flashbacks). Engelhard, Van den Hout, Janssen y Van Der Beek (2010) mostraron que esforzar la memoria de trabajo, tal y como se hace en el EMDR, es capaz de reducir la viveza y la emocionalidad de las imágenes negativas de acontecimientos temidos futuros (los llamados flash-forwards). Este descubrimiento ha abierto todo un campo nuevo de aplicación para el EMDR (Engelhard et al., 2011; Logie y De Jongh, en prensa).

\section{El enfoque del primer método con la psicosis: EMDR dirigido a las experiencias directamente conectadas con los síntomas}

Cuando hay conexiones evidentes y directas entre ciertos acontecimientos de la vida y el desarrollo y 


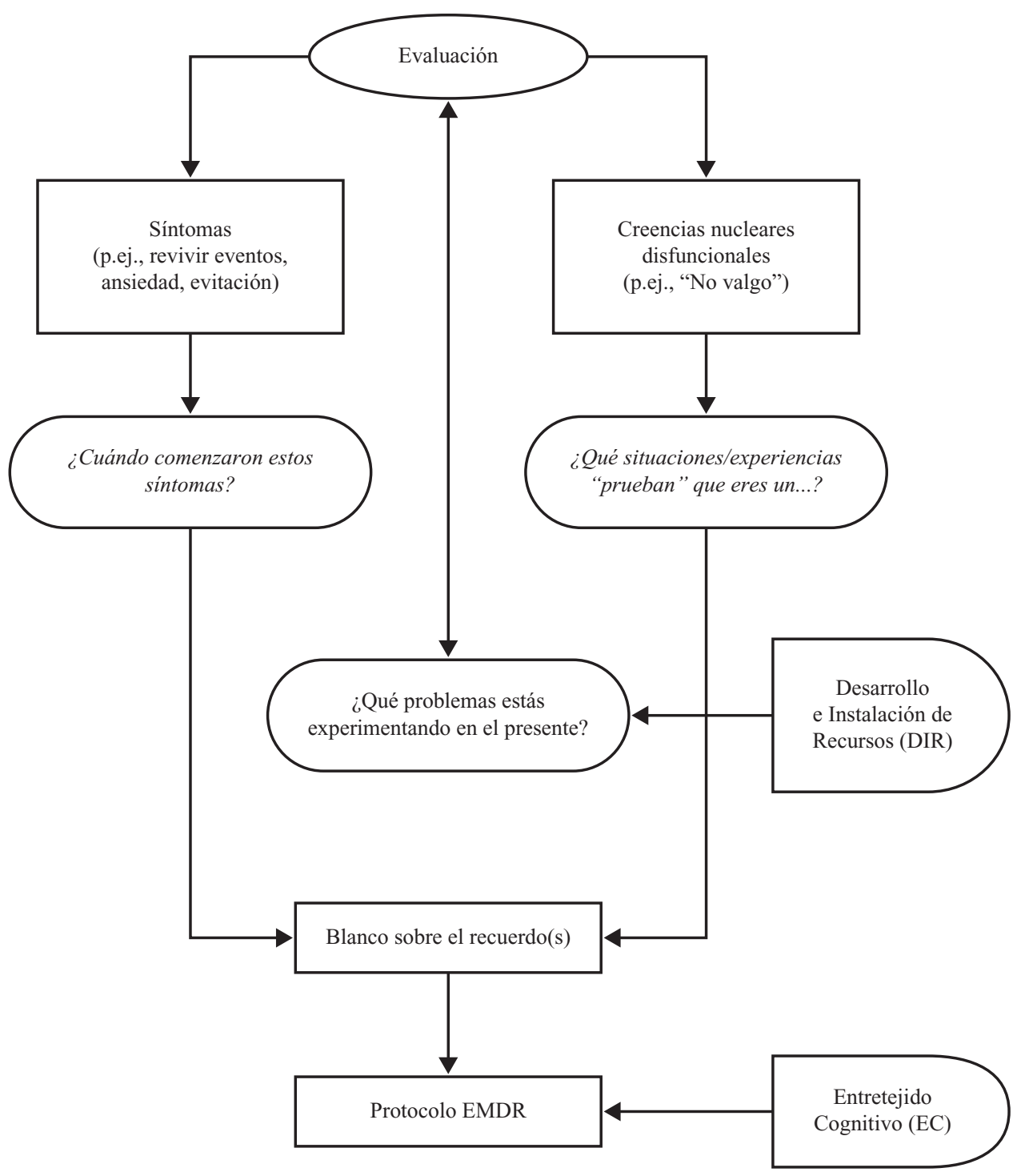

FIGURA 1. El enfoque de dos métodos de EMDR. Adaptado de De Jongh, A., Ten Broeke, E., \& Meijer, S. (2010). Two method approach: A case conceptualization model in the context of EMDR. Journal of EMDR Practice and Research, 4(1), 12-21.

la persistencia de síntomas psicóticos, se puede utilizar el primer método. En esencia, no hay diferencia en la forma en que se aplica el EMDR en el tratamiento de los trastornos de ansiedad (de Jongh y Ten Broeke, 2007).

A través del primer método, se hace blanco sobre las experiencias que están directamente relacionadas con el inicio o empeoramiento de los síntomas psicóticos o con el contenido de estos síntomas. La mayoría de los clientes son capaces de identificar los eventos estresantes que relacionan subjetivamente con su paranoia o sus alucinaciones. Asimismo, suele recordarse claramente el momento concreto en que la confusión de un cliente fue reemplazada por una convicción delirante. Los recuerdos de los eventos etiológicos y agravantes pueden formularse de manera significativa en una línea de tiempo y luego procesarse utilizando el protocolo estándar de EMDR (De Jongh et al., 2010; Shapiro, 2001). En realidad, dibujar esta línea de tiempo con un cliente puede ser muy revelador, poniendo los hechos en el eje $\mathrm{X}$ y el síntoma psicótico en el eje Y (Figura 2).

\section{Ejemplo de caso: Primer método con TEPT comórbido}

Judy era una mujer de 46 años con diagnóstico de trastorno esquizoafectivo desde hacía más de 20 años. Había recibido asistencia social intensiva y sus síntomas psicóticos habían sido gestionados en su mayoría con medicación. Trabajaba en un restaurante 12 horas a la semana, donde aún experimentaba ideas de 


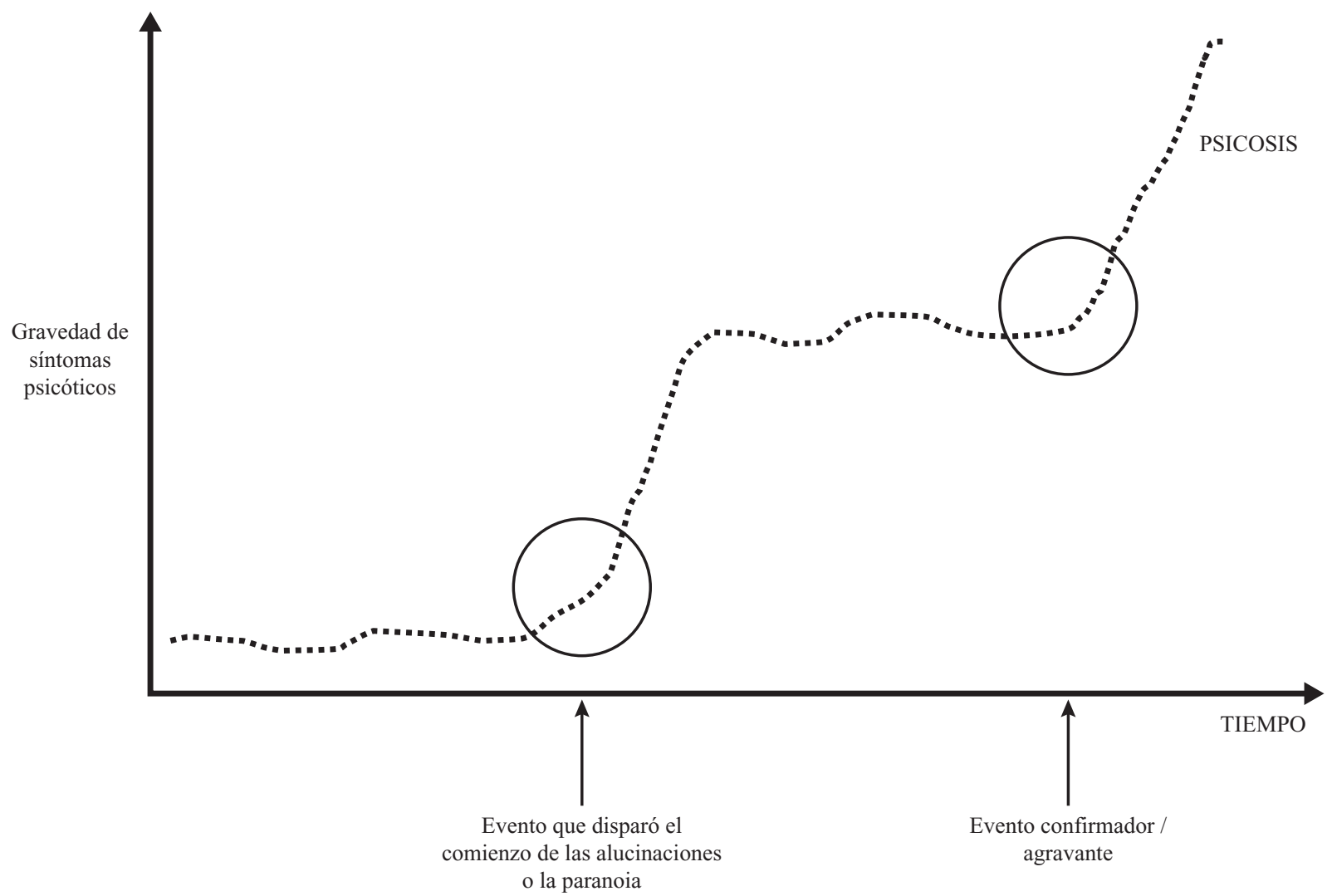

FIGURA 2. Enfoque del primer método de EMDR en psicosis.

referencia. Cuando estaba estresada, a veces reaccionaba con estallidos de agresividad.

Un programa de televisión sobre un violador activó algunos de los recuerdos de Judy. Cuando tenía 19 años, sufrió acoso sexual en una playa. Al lograr huir, pudo evitar ser violada. Sin embargo, el programa de televisión empeoró los flashbacks de este evento además del insomnio, la hiperactivación y otros síntomas de TEPT que se encontraban latentes. Empezó a sentir intensamente que había escapado por los pelos de una muerte segura ese día en concreto. Cuando fue evaluada con la Escala de TEPT Administrada por el Clínico (CAPS; Blake et al., 1990), cumplía los criterios para el TEPT.

Seleccionar el evento y los blancos para el EMDR no fue complicado en este caso: un evento único y claro con flashbacks de la cara del agresor. La cognición negativa $(\mathrm{CN})$ asociada con el blanco era "estoy desprotegida", la puntuación de la escala de unidades subjetivas de perturbación (SUD) fue de $9(0=$ ninguna perturbación, $10=$ la peor posible). El proceso de desensibilización transcurrió rápidamente y sin obstáculos relevantes. El SUD bajó a 5, luego a 3, luego a 1 y luego a 0 . La validez de la cognición positiva (CP: "puedo con esto") aumentó hasta el máximo, todo ello en una sola sesión. La sesión terminó con el procedimiento de plantilla de futuro: Judy imaginaba estar viendo una noticia en la televisión sobre un violador y un asesino. Rápidamente juzgó que sería capaz de lidiar con esto.

En la siguiente sesión, unos días más tarde, Judy indicó que estaba sorprendida por el resultado. Hablar del recuerdo ya no le disparaba reacciones emocionales intensas. Sin embargo, había evitado ver la televisión la semana anterior, por miedo a que pudiesen volver los flashbacks. Se realizó una nueva sesión de plantilla de futuro y se le asignó una tarea de exposición real: Judy y el terapeuta buscaron y leyeron noticias de casos de violaciones en internet.

Al hacer un seguimiento, 6 meses después de terminar el tratamiento, Judy se había recuperado aún más y había abandonado sus conductas evitativas. Había dejado de dormir con la luz encendida, no evitaba la televisión ni los periódicos y usaba el transporte público sin problema. Ya no cumplía los criterios para el TEPT en el CAPS.

\section{Ejemplo de caso: Primer método con voces}

Francis era un refugiado de Sierra Leona en busca de asilo. Había sido diagnosticado con esquizofrenia paranoide hacía 8 años. Durante la evaluación, indicó escuchar voces que le amenazaban con frases como 
"te vamos a cortar las manos" y "te vamos a matar". Estaba convencido de que esas voces pertenecían a personas que de hecho estaban buscándole y esto le producía suspicacia y mucha ansiedad. Se sobresaltaba fácilmente, sufría de pesadillas y tenía dificultad para concentrarse. Las voces empezaron después de ver a los rebeldes quemar a gente y cortarles las manos. Los síntomas psicóticos (alucinaciones auditivas e interpretación paranoide) estaban directamente relacionados con esas experiencias traumáticas, tanto en origen como en contenido. Usando el enfoque del primer método, se formuló la hipótesis de que el reprocesamiento de esos recuerdos tendría un efecto positivo sobre sus síntomas psicóticos.

El terapeuta ofreció a Francis información sobre las consecuencias de experimentar un trauma. Compartió su hipótesis de que las voces estaban directamente relacionadas con las experiencias traumáticas en Sierra Leona y que esperaba que el tratamiento del trauma pudiera resultar en una reducción de la angustia. Francis identificó dos recuerdos diana muy perturbadores: (a) Ver cómo quemaban viva a una persona y (b) ver cómo le cortaban a alguien las dos manos. La CN que acompañaba a ambas imágenes fue "estoy en peligro". Se utilizó el protocolo estándar de EMDR para desensibilizar y las puntuaciones del SUD empezaron a declinar.

Las alucinaciones complicaron el tratamiento. Las voces amenazaban a Francis continuamente durante los movimientos oculares, bloqueando la reducción de la angustia experimentada. Francis no veía las voces como síntomas de un trastorno. Estaba convencido de que estas voces eran los auténticos asesinos y que estaban en Holanda, con lo que sentía que su vida corría un gran peligro. El terapeuta aplicó una intervención cognitiva que puede verse como un entretejido cognitivo extenso. Desafió las creencias de Francis sobre la posibilidad de que los asesinos que había visto en Sierra Leona hacía 10 años le estuviesen buscando ahora. Haciendo un cálculo probabilístico acumulativo, Francis se dio cuenta de que tendrían que cumplirse unas cuantas condiciones y de que la posibilidad de que este fuera el caso era bastante baja. Sin embargo, todavía pensaba que era posible, se sentía más seguro y se continuó con el EMDR. Las puntuaciones del SUD en ambos blancos bajaron a 0 en unas pocas sesiones.

La integración de psicoeducación, intervenciones cognitivas y EMDR ayudó a Francis a cambiar su valoración de las voces. La idea de que las voces realmente era flashbacks muy vívidos comenzó a ganar credibilidad poco a poco, lo cual le motivó a comenzar a ignorarlas. Esto redujo su preocupación respecto a ellas. Esto dio como resultado que Francis se encontrara mucho mejor y las voces tuvieran menos peso sobre su funcionamiento.

\section{Ejemplo de caso: Primer método con delirios}

Leonard era un hombre de 48 años con esquizofrenia paranoide; fue diagnosticado tras la aparición de síntomas después de un robo que puso en peligro su vida hacía unos años; antes de esto, nunca había estado en contacto con los servicios de salud mental. El agresor le amenazó con un cuchillo y, en el momento, Leonard pensó que había escapado por poco de la muerte. Unas semanas más tarde, Leonard se encontró con su agresor en compañía de unos amigos. El agresor miró a Leonard e hizo un gesto amenazador con la mano (cortarle la garganta) y todos los amigos del agresor se rieron. Leonard concluyó: "Es un pandillero y van a matarme". Desde ese día, Leonard andaba por la calle extremadamente alerta. Esta hipervigilancia se convirtió en delirio paranoide, hasta el punto de pensar que todos las personas de color formaban parte de una conspiración para asesinarlo. Leonard se aisló, su empresa quebró y su esposa le abandonó. Cuando buscó tratamiento en el servicio de salud mental, estaba totalmente convencido de que todas las personas de piel oscura en su ciudad natal le perseguían. Leonard no experimentaba síntomas de revivencia como flashbacks o pesadillas. Pero siguió preocupándose por su seguridad y por estar amenazado. A causa de estos síntomas, se le diagnosticó esquizofrenia paranoide y su psiquiatra le recetó medicación antipsicótica. Leonard comenzó a preocuparse algo menos por sus vecinos de color, pero sus convicciones no cambiaron y no salía de su casa. Leonard fue derivado a terapia cognitivo-conductual (TCC).

Leonard y su terapeuta comenzaron a trabajar en la formulación del caso. Estaba claro para Leonard que había dos experiencias importantes relacionadas con su miedo actual a la gente de color: (a) El robo y (b) haber ido amenazado en plena calle. El terapeuta comparó las quejas de Leonard con las de alguien que hubiera desarrollado una fobia a los perros después de haber sido mordido por uno y Leonard se sintió comprendido. El tratamiento psicológico comenzó con EMDR para esas experiencias, con el plan de continuar con TCC.

El primer blanco fue la imagen del agresor poniéndole el cuchillo en la garganta. La CN al mirar esta imagen era "estoy indefenso". La puntuación SUD comenzó en 10 y se redujo a un 0 en una sola sesión. La validez de la cognición (VOC, "puedo manejar esto") subió de un 3 a un 7 . El terapeuta instaló una plantilla de futuro para reducir su miedo a pasear a su perro y encontrarse con vecinos de color. Leonard llegó a la 


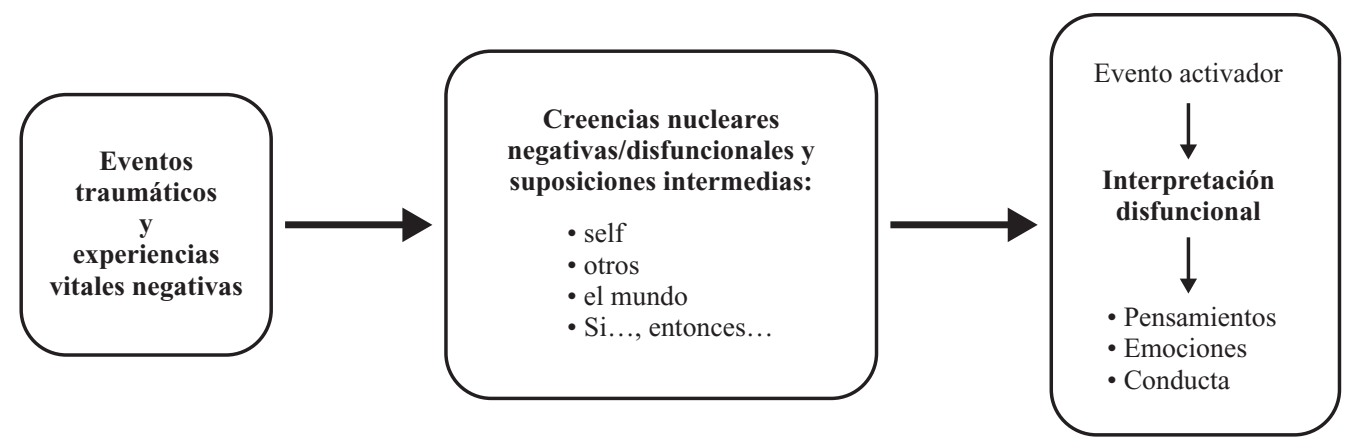

FIGURA 3. Enfoque del segundo método de EMDR en la psicosis.

conclusión de que era una persona fuerte y se encontró motivado para empezar a pasear él mismo a su perro.

En la siguiente sesión, Leonard refirió menos ansiedad y preocupación. Había paseado al perro él solo varias veces y pudo ignorar con éxito a hombres de color. El segundo blanco fue su recuerdo del agresor haciendo el gesto de amenaza con sus amigos. La CN era "estoy en peligro" y la CP deseada era "ahora estoy a salvo". La plantilla de futuro se centró en hacer la compra en el supermercado local, al que acudían muchos inmigrantes. Una vez más, Leonard concluyó que era fuerte.

Con EMDR se desensibilizaron con éxito los recuerdos diana y Leonard declaró que tenía dudas sobre la veracidad de sus sospechas. Por lo tanto, el terapeuta aplicó técnicas cognitivas. Leonard y su terapeuta reunieron todas las pruebas que apoyaban su creencia de que la banda todavía quería asesinarlo. También miraron de cerca los temas que contradecían esta creencia, por ejemplo, el hecho de que habían pasado varios años sin un solo ataque. Después de algunos experimentos conductuales, Leonard continuó la exposición in vivo.

El grupo de agresores potenciales imaginados se redujo rápidamente. Finalmente, Leonard sólo temía al autor del robo y sus tres compañeros. Fue capaz de moverse libremente por su barrio y volver a trabajar media jornada. Leonard todavía se asegura de no encontrarse con el agresor. El terapeuta trató de motivar a Leonard para un experimento conductual definitivo: indagar para comprobar si el agresor todavía seguía interesado en él.

Leonard rechazó esta opción y la terapia terminó de mutuo acuerdo.

\section{Enfoque del segundo método en la psicosis: EMDR dirigido a las experiencias que ejercen una influencia indirecta sobre las interpretaciones psicóticas de eventos activadores del presente}

Los supuestos básicos sobre uno mismo, los demás y el mundo son factores importantes en el desarrollo y mantenimiento de la psicosis (Garety, Kuipers, Fowler, Freeman y Bebbington, 2001). Estos esquemas negativos se desarrollan como consecuencia de acontecimientos vitales negativos, tales como adversidad en la niñez, intimidación y experimentar discriminación. El enfoque del segundo método de EMDR tiene como objetivo identificar y cambiar estas creencias nucleares negativas disfuncionales (De Jongh et al., 2010).

En primer lugar, un procedimiento de evaluación pretende conceptualizar los problemas de los clientes. La figura 3 presenta el modelo general. Se evalúan las creencias nucleares y los supuestos intermedios, las experiencias vitales relevantes y las respuestas disfuncionales.

Por definición, las formulaciones de los casos varían para cada individuo. Sin embargo, el terapeuta puede tener en cuenta que, sobre todo, los traumas de la infancia caracterizados por la intención de hacer daño (por ejemplo, abuso sexual, abuso físico, acoso, discriminación), la negligencia y el ser criado en una institución están causalmente vinculados con síntomas de psicosis en adultos (Bentall, Wickham, Shevlin y Varese, 2012; Varese et al., 2012). Para ilustrar la forma en que el EMDR puede ser conceptualizado en la psicosis a través del enfoque del segundo método, se resumen tres formulaciones de casos individuales de EMDR simplificadas en la Tabla 2.

Sobre la base de la formulación del caso, el EMDR a través del enfoque del segundo método se dirige a aquellos acontecimientos traumáticos de la vida que el cliente siente como la evidencia más convincente de que sus creencias nucleares y suposiciones intermedias disfuncionales son ciertas. Cada una de estas pruebas se reprocesa con el protocolo estándar de EMDR. Se reprocesan las CNs disfuncionales (teniendo en cuenta que cada situación traumática puede tener una $\mathrm{CN}$ y $\mathrm{CP}$ diferente) y se instalan CPs más funcionales. El efecto que se pretende es que el conglomerado de nuevas CPs ayude a refutar las creencias 
TABLA 2. Breves ilustraciones del enfoque del segundo método de EMDR en la psicosis

\begin{tabular}{|c|c|c|c|c|c|}
\hline \multirow[b]{2}{*}{ Trauma } & \multirow{2}{*}{$\begin{array}{l}\text { Creencias } \\
\text { centrales o } \\
\text { supuestos } \\
\text { intermedios }\end{array}$} & \multirow[b]{2}{*}{ Evento activador } & \multicolumn{3}{|c|}{ Respuesta disfuncional } \\
\hline & & & Cognición & Emoción & Conducta \\
\hline $\begin{array}{l}\text { Castigos de un } \\
\text { padre per- } \\
\text { feccionista }\end{array}$ & "Soy un fracaso." & $\begin{array}{l}\text { Oír una voz } \\
\text { (“iEh, idiota!”) }\end{array}$ & $\begin{array}{l}\text { "Lo sabía. No puedo } \\
\text { hacer nada bien." }\end{array}$ & Triste & $\begin{array}{l}\text { Me aíslo social- } \\
\text { mente; le doy } \\
\text { vueltas a la } \\
\text { cabeza. }\end{array}$ \\
\hline $\begin{array}{l}\text { Abuso físico } \\
\text { de madre y } \\
\text { hermanos }\end{array}$ & $\begin{array}{l}\text { "Estoy en peligro; } \\
\text { no puedo con- } \\
\text { fiar en nadie." }\end{array}$ & $\begin{array}{l}\text { La suegra critica } \\
\text { como llevo } \\
\text { mi casa. }\end{array}$ & $\begin{array}{l}\text { "Me odia, me quiere } \\
\text { matar." }\end{array}$ & $\begin{array}{l}\text { Miedo, } \\
\text { vergüenza }\end{array}$ & $\begin{array}{l}\text { Llamo a mi marido } \\
\text { para que me pro- } \\
\text { teja de su madre } \\
\text { asesina. }\end{array}$ \\
\hline $\begin{array}{l}\text { Abuso sexual } \\
\text { en la } \\
\text { infancia }\end{array}$ & "Soy débil." & $\begin{array}{c}\text { Voces imperativas } \\
\text { (“iTírate por las } \\
\text { escaleras!”) }\end{array}$ & $\begin{array}{l}\text { "Tengo que rendirme } \\
\text { a ellos o me harán } \\
\text { más daño aún." }\end{array}$ & Triste, miedo & $\begin{array}{l}\text { Auto-mutilación; } \\
\text { hago lo que me indi- } \\
\text { can las voces. }\end{array}$ \\
\hline
\end{tabular}

nucleares disfuncionales generales. También ayudan al cliente a reconocer que sus síntomas son respuestas comprensibles frente a experiencias extraordinariamente adversas de la vida.

Ejemplo de caso: Enfoque del segundo método con voces

Irene era una mujer de 49 años diagnosticada con esquizofrenia y trastorno depresivo a los 20 años. Sufrió varios episodios psicóticos y estuvo hospitalizada, de media, una vez al año. Irene recibió asistencia social intensiva para su caso y vivía en un casa refugio. A los 40 años, las cosas empezaron a mejorar para Irene. Los episodios psicóticos ocurrían con menor frecuencia, consiguió su propio apartamento y se casó con un hombre que había conocido durante una de sus hospitalizaciones. El año pasado, las cosas se torcieron cuando el marido de Irene se suicidó mientras ella estaba hospitalizada. Ella había apagado su teléfono móvil porque no él no dejaba de llamarla repetidamente. Esa noche se suicidó. Esto dio lugar a una larga hospitalización durante la cual Irene intentó suicidarse más de una vez. Fue dada de alta 10 meses más tarde. A continuación fue derivada a psicoterapia. Irene oía voces que la insultaban y acusaban de hacer daño a otras personas. Estaba deprimida y tenía muchas ideas suicidas. Irene tenía creencias nucleares negativas muy arraigadas sobre sí misma, los demás y el mundo. Su creencia nuclear más disfuncional era "soy una mala persona”. Muchas experiencias traumáticas diferentes contribuían a esta creencia central y el terapeuta introdujo el enfoque del segundo método para determinar qué recuerdos reprocesar. Se le preguntó a Irene qué experiencias de vida todavía sentía como evidencia de su creencia nuclear. Esta prueba era parte de su formulación del caso (véase la figura 4): Cuando Irene tenía 7 años, un hermano la obligó a tener relaciones sexuales varias veces. Irene se acostumbró a ello y sentía cada vez más indiferencia al respecto. El mismo hermano murió en un accidente de coche cuando Irene tenía 12 años. El día después de su muerte, Irene empezó a escuchar voces. Unos años más tarde, Irene se quedó congelada y fue incapaz de hablar en el funeral de su padre. Su madre etiquetó este momento como el peor momento del día y el punto de partida de su depresión que duró 4 años. Por último, estaba el hecho de que Irene había apagado su teléfono móvil la noche en que su marido se suicidó.

La terapia EMDR se centró en los siguientes blancos: No contestar al teléfono cuando el marido estaba entrando en pánico (CN: "soy una mala persona"); tener relaciones sexuales con el hermano (CN: "soy una puta estúpida"); y escuchar los comentarios de la madre en su discurso fúnebre (CN: "no valgo"). Uno a uno, los blancos fueron procesados y se instalaron las CPs. En conjunto, las CPs ayudaron a disminuir la intensidad y la credibilidad de la creencia central negativa, "soy una mala persona". Las voces se intensificaron durante las primeras semanas de tratamiento, pero el terapeuta normalizó esta respuesta. Irene y su terapeuta hablaron sobre qué hacer en esta situación y estuvieron de acuerdo en continuar con la terapia EMDR.

A medida que avanzaba el tratamiento EMDR, Irene comenzó a cuestionar y enfrentarse a las voces. Aprendió a verlas como "fantasmas de su pasado" y se volvió menos sensible a ellas. Aunque disminuyeron los sentimientos de culpa, el miedo a sentirse abrumada de nuevo por las voces seguía siendo intenso. Para solucionar esto, el terapeuta e Irene construyeron 


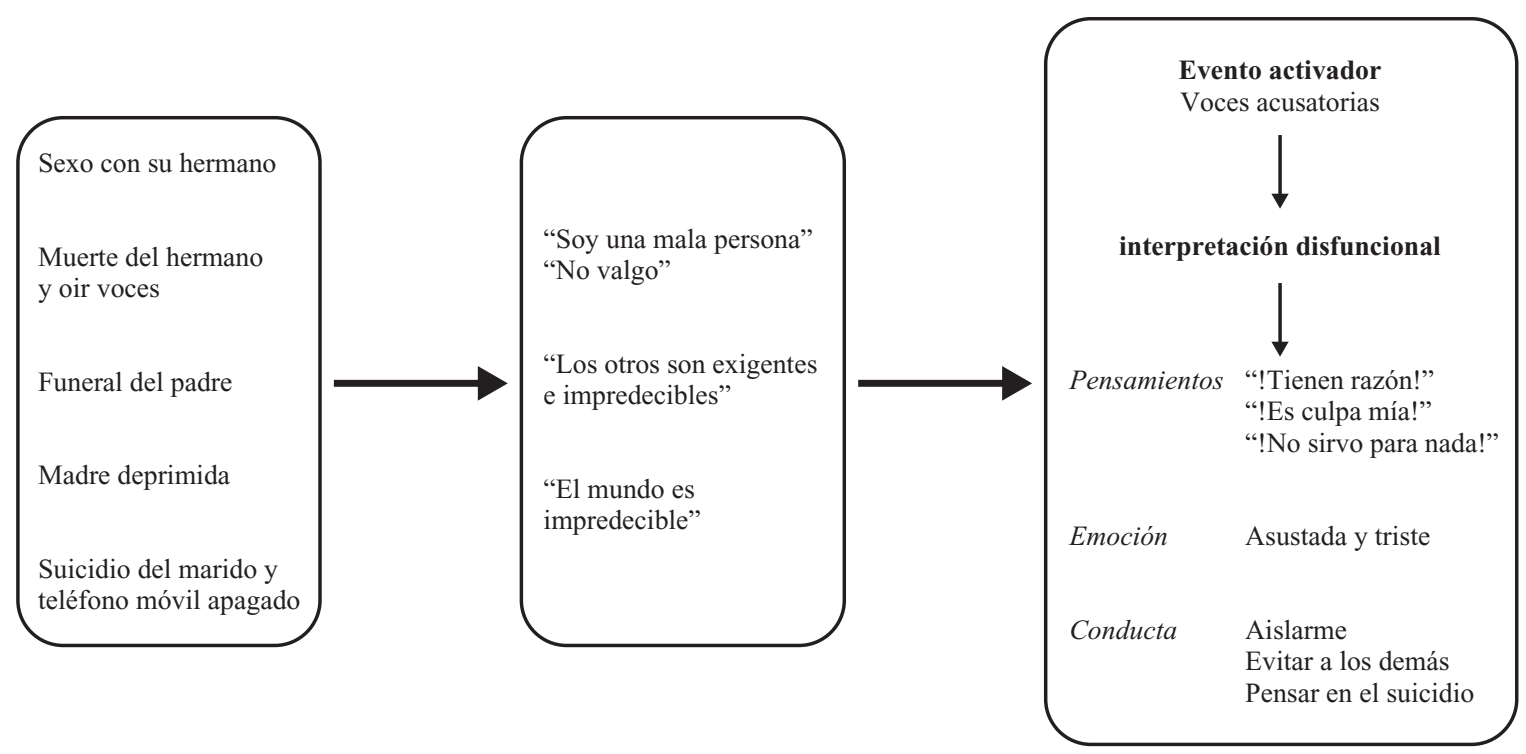

FIGURA 4. Formulación del caso con el enfoque del segundo método: Irene.

una imagen futura imaginaria que usaron como diana para el reprocesamiento EMDR (ver la sección de "Imágenes en la psicosis"). La imagen era de Irene, sentada en su habitación, rodeada de voces que provenían de su madre, su hermano, su padre, las almohadas, los cables y las mesas. La CN era "estoy indefensa". El SUD bajó a 0 en dos sesiones. La CP ("puedo lidiar con esto") fue instalada con dos tandas de movimientos oculares. Una serie de plantillas de futuro estaba dirigida a situaciones específicas para ayudar a Irene a participar en actividades diarias normales, como no evitar a los hombres y volver a encontrarse con su hermana. Al final del tratamiento, Irene seguía escuchando voces, pero les prestaba menos atención y estaba menos preocupada por el miedo a sentirse abrumada. Su autoestima mejoró significativamente y se sentía menos deprimida.

\section{Ejemplo de caso: Enfoque del segundo método con delirios paranoides}

Albert era un hombre de 36 años. Hace diez años, a Albert se le diagnosticó esquizofrenia paranoide cuando empezó a oír voces que le insultaban. Sospechaba que su vecino estaba detrás de esto. Se enfrentó a su vecino, quien le dijo a Albert que se callase y dejase sus "acusaciones locas". Los dos hombres terminaron peleando a puñetazos y Albert recibió una paliza. Albert fue derivado a la custodia de los servicios de salud mental. La medicación hizo que las voces desapareciesen. Sus pensamientos paranoicos, sin embargo, se mantuvieron. Albert estaba aún convencido de que su vecino y sus amigos le estaban observando y esperando para matarlo en venganza por sus acusaciones. Albert se quedaba en casa lo más posible y sólo salía en bicicleta para poder huir rápidamente si fuera necesario.

En TCC, Albert aprendió a cuestionar y dudar de sus creencias delirantes. Albert reveló importantes experiencias vitales. Sus padres eran alcohólicos y le descuidaban. Albert fue testigo en varias ocasiones de los golpes que su padre propinaba a su madre. Sus compañeros de la escuela primaria le intimidaban. En el instituto, logró desarrollar una amistad con un compañero de clase, pero al año siguiente, cuando sus compañeros le golpearon de nuevo y le arrojaron a un contenedor de basura, su "mejor amigo" se rió. Todo esto hizo que apareciesen sus creencias nucleares: (a) "No se puede confiar en los demás", "soy débil" y (b) "los demás son malévolos y no se puede confiar en ellos." Ver la figura 5 para la formulación del caso.

Albert expresó al terapeuta su convicción de que muchas de sus experiencias en la vida demostraban que sus creencias eran verdaderas. Se tomó la decisión de aplicar EMDR a través del enfoque del segundo método. Albert y su terapeuta enumeraron las experiencias traumáticas específicas que habían alimentado la creencia central "soy débil" de Albert: mi padre golpea a mi madre, me congelo $(\mathrm{CN}$ : "estoy indefenso"); una experiencia de acoso escolar en la escuela primaria (CN: "soy débil"); ser golpeado y arrojado al basurero, mi mejor amigo se ríe (CN: "soy tonto"); y ser golpeado por el vecino (CN: "estoy en peligro"). Cada una de estos recuerdos fue reprocesado con el protocolo estándar de EMDR. Durante el procesamiento EMDR, Albert espontáneamente 


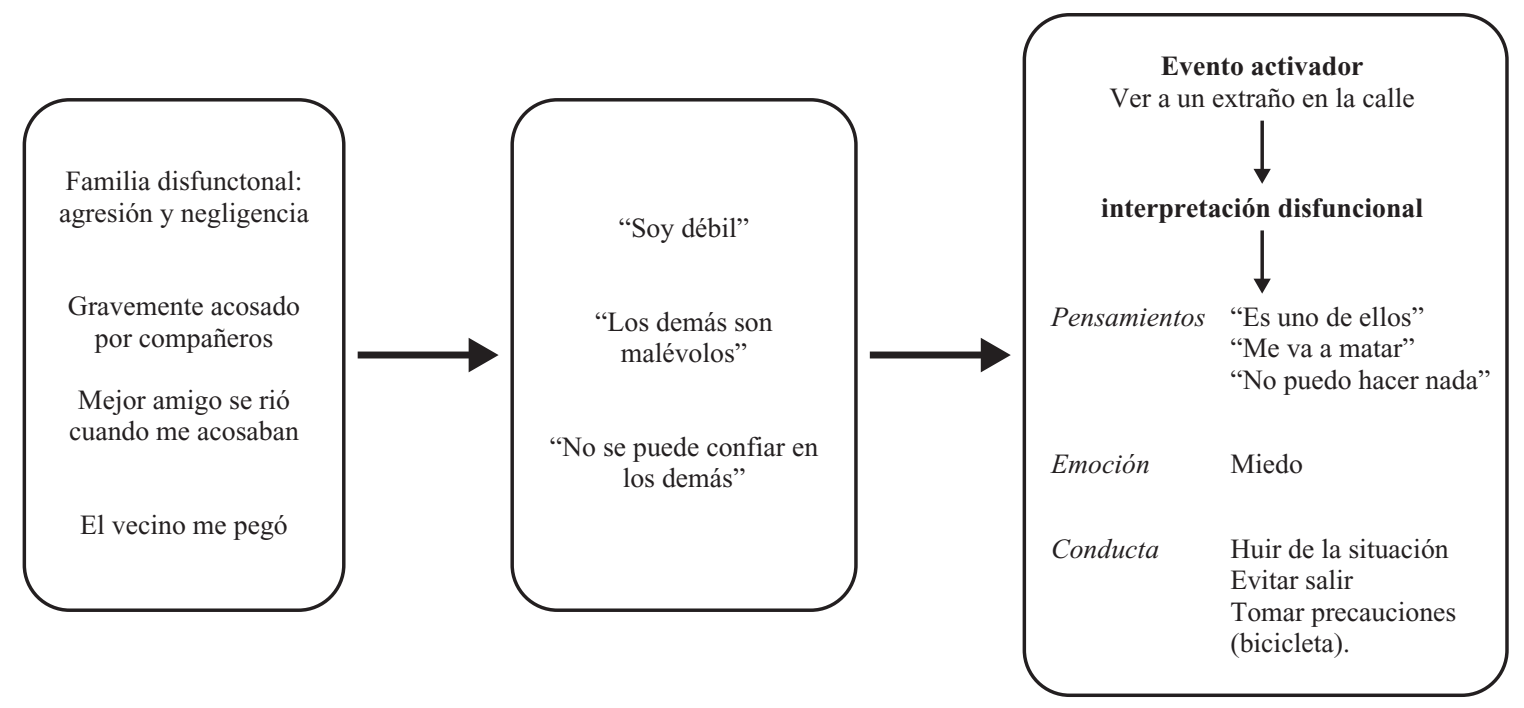

FIGURA 5. Formulación del caso con el enfoque del segundo método: Albert.

volvió a escribir el guión de algunos de los blancos, imaginando que protegía a su madre de su padre abusivo y que luchaba contra su vecino agresivo.

Su creencia nuclear de que "la gente es malvada" fue abordada de la misma manera: haciendo una lista de sus experiencias pasadas que servían como evidencia de esta creencia central negativa, aplicando el procedimiento EMDR e instalando las cogniciones positivas. Después de todo esto, Albert pudo sentir que sus creencias negativas eran menos convincentes. Esto aumentó su motivación para poner a prueba sus predicciones paranoides en una serie de experimentos conductuales que fueron apoyados con EMDR, reprocesando las imágenes negativas de estas predicciones. Al final del tratamiento, Albert fue capaz de salir de casa para pasear o ir de compras. Su preocupación paranoide había disminuido considerablemente.

\section{Imágenes en la psicosis: EMDR dirigido a las expectativas atemorizantes y poco realistas 0 a las imágenes negativas relacionadas con la psicosis}

El "tercer método" de EMDR está dirigido a dos de los tipos de imágenes que se han visto que son más dominantes en la psicosis (Morrison et al., 2002): (a) las imágenes de las catástrofes temidas (es decir, el flashforward) y (b) las visualizaciones del origen, la apariencia, o el contenido percibido de un síntoma (es decir, el evento activador).

Reprocesar "el peor de los casos" (a menudo supuestos intermedios, "si hago ..., entonces va a suceder...") con EMDR puede reducir la ansiedad y las conductas evitativas asociadas. En este procedimiento
EMDR, al cliente se le pide que describa lo que sería el peor de los casos. En algunos clientes, se trata de imágenes intrusivas con las que están muy familiarizados (es decir, flashforwards intrusivos), en otros esta imagen del blanco se crea dentro de la sesión. A continuación, el cliente y el terapeuta identifican la imagen más desagradable de esta situación, es decir, la forma habitual de selección de blancos, pero en este caso no sobre un recuerdo sino sobre una imagen fantasiosa de algún desastre. La CN está, por definición, en el dominio de pérdida de control (es decir, no tener poder sobre la imagen intrusiva), la CP es "puedo manejar esto" y el SUD normalmente es lo suficientemente alto como para impulsar el procesamiento del flashforward del cliente. Se utiliza el protocolo habitual para desensibilizar.

El segundo tipo de imágenes relacionadas con la psicosis sobre las que se puede hacer blanco con EMDR son las imágenes mentales que el cliente tiene de la causa, la apariencia o el contenido percibidos de un síntoma psicótico. En el contexto de las voces o la paranoia, un cliente puede, por ejemplo, formarse una imagen mental de sus "agresores". Reprocesar esta imagen puede reducir la implicación emocional y la preocupación. Una imagen diana podría ser, por ejemplo, que el cliente se vea a sí mismo sentado en la cama con un hombre al lado que le está gritando cosas desagradables a través de un altavoz. Se aplica EMDR de la manera regular. Con este tipo de imágenes, la $\mathrm{CN}$ y la CP pueden estar en cualquier dominio.

Se recomienda no utilizar flashforwards e imágenes hasta que el cliente haya desarrollado al menos cierto conocimiento de la posible naturaleza alucinatoria de sus percepciones. Para que el reprocesamiento de 
las imágenes sea efectivo, el cliente tiene que tener por lo menos algo de conciencia del hecho de que las expectativas temidas pudieran no ser realistas, o de que las experiencias intrusivas realmente no deberían recibir tanta atención. Durante el procesamiento, la perspectiva adulta, sana y matizada de la realidad ha de volverse dominante. Cuando disminuye la emotividad, se genera el espacio para la distancia y el matiz. De modo similar a un cliente con trastorno de estrés postraumático, el cliente con síntomas psicóticos empieza a darse cuenta de que no existe una amenaza presente, de que ahora está a salvo. Por lo tanto, lo mejor es empezar con trabajo cognitivo y luego usar EMDR con las imágenes cuando el cliente tenga al menos alguna duda sobre sus apreciaciones psicóticas. Esto puede entonces, si es necesario, continuarse con intervenciones cognitivo-conductuales, tales como experimentos conductuales o tareas de exposición.

\section{Ejemplo de caso: Voces e imágenes}

Marjorie tenía 21 años, un diagnóstico de esquizofrenia paranoide y se encontraba agobiada por sus alucinaciones auditivas verbales. Los síntomas comenzaron hace 4 años cuando murió su abuelo. Se sentía muy perdida y sola, y fue incapaz de expresar sus emociones. Se sentía responsable del sufrimiento de su familia. Por encima de todo, se preocupaba por su hermana menor. La primera vez que oyó la voz de una mujer, se encontraba en el baño. La voz le dijo que se suicidase y la amenazó con hacerle daño a su hermana si no lo hacía. Marjorie comenzó a pensar que esa voz era un espíritu poderoso que en realidad podía matar a su hermana. Para evitar que esto sucediese, Marjorie realizó tres intentos de suicidio muy graves. Estaba ansiosa, desgarrada por la culpa, sufría de disociación y se auto-mutilaba. El principal desencadenante de estos síntomas no era la voz en sí, sino una imagen intrusiva de su hermana muerta en la cama.

El EMDR se centró en la intrusión de su hermana muerta, porque se formuló la hipótesis de que esto reduciría los síntomas. La imagen se volvió menos intensa y los síntomas comenzaron a disminuir. La motivación de Marjorie para investigar sus creencias sobre la voz aumentó con técnicas de TCC. Se atrevió a probar qué pasaría si no obedecía las instrucciones de la voz. Descubrió que una menor sumisión en realidad no daba lugar a que sus seres queridos fuesen dañados (especialmente su hermana). Por lo tanto, se le hizo más fácil ignorar la voz y se redujeron tanto la frecuencia como la intensidad de las alucinaciones.
Ejemplo de caso: Delirios e imágenes

Faye tenía 45 años y había sido diagnosticada con trastorno esquizoafectivo unos 20 años atrás. Hace un año, comenzó a acumular deudas. Para pagar estas deudas y ahorrar algo de dinero, alquiló su ático a un estudiante. Tuvo una recaída de psicosis y comenzó a desarrollar delirios sobre el inquilino y, especialmente, sobre un amigo suyo que era rastafari. Se obsesionó con la magia negra y tenía miedo de que estuvieran haciéndole vudú. Faye fue internada en un hospital psiquiátrico.

Durante el ingreso, Faye recibió medicación antipsicótica y TCC, lo que le ayudó a recuperarse. Faye fue dada de alta del hospital 3 meses después y continuó con TCC. Realizó varios experimentos conductuales y concluyó que el inquilino no tenía malas intenciones hacia ella. Dado que sabía que era difícil para ella enfrentarse a su amigo, dejó de verle en la casa. Varias veces, Faye intentó decirle al inquilino que podía invitar a su amigo otra vez. Pero cuando trataba de hacerlo, le venía una imagen intrusiva de un muñeco de vudú al que le sangraban los ojos. Aunque ya no estaba convencida del vudú, las imágenes la asustaban y le impedían llevar a cabo su plan.

El terapeuta propuso utilizar EMDR para esta imagen. La CN formulado era "estoy en peligro". El SUD bajó y la imagen diana cambiaba rápidamente. La primera vez que regresaron al blanco, la imagen había cambiado: había costras de sangre en los ojos. La segunda vez, Faye se echó a reír. Las costras habían sido reemplazadas por margaritas y el SUD era 0 . La plantilla de futuro era de Faye abriendo la puerta para recibir la visita de su inquilino y su amigo.

Unos días más tarde, Faye envió un e-mail a su terapeuta:

Esta tarde mi inquilino y su amigo pasaron a hacerme una visita. Fue muy agradable. No sé si fue el EMDR que funcionó o que yo recordé por adelantado deliberadamente la imagen de la margarita, pero fue muy bien. Muchas gracias, Faye.

\section{Obstáculos y estrategias de tratamiento relacionadas}

Se presentan varios obstáculos que pueden ser específicos de uso de EMDR en clientes con psicosis, acompañados de posibles estrategias de tratamiento que pueden ser útiles (véase también la tabla 3).

\section{Traumatización continuada debido a} experiencias psicóticas

Cuando un cliente atribuye alucinaciones auditivas, como por ejemplo voces, al agresor real de una 
TABLA 3. Estrategias adaptativas para EMDR en clientes con psicosis

\begin{tabular}{lc}
\hline Obstáculo & Estrategias \\
\hline Concentración limitada & Repetir las instrucciones cuando haga falta durante la sesión. \\
Poca energía y poca atención continuada & Trabajar despacio, posiblemente con sesiones más cortas. \\
Poca memoria de trabajo & $\begin{array}{c}\text { Prevenir la inundación completa de la memoria de trabajo, } \\
\text { bien por flashbacks traumáticos o un estímulo distractor. }\end{array}$ \\
& $\begin{array}{l}\text { La distracción debería parecerse a la intrusión de la imagen } \\
\text { diana. Variar el estímulo distractor en consonancia. }\end{array}$ \\
$\begin{array}{l}\text { Disminución de la expresión afectiva } \\
\text { Hablar abiertamente de cómo puntuaría el cliente su angustia } \\
\text { externas de las experiencias psicóticas } \\
\text { interrumpe los efectos del aprendizaje del EMDR }\end{array}$ & $\begin{array}{c}\text { Terapia cognitivo-conductual, entretejidos cognitivos o de- } \\
\text { sarrollo e instalación de recursos. }\end{array}$ \\
\hline
\end{tabular}

experiencia traumática del pasado, este cliente puede continuar sintiéndose amenazado e inseguro. Del mismo modo, los delirios paranoides pueden generar una traumatización continuada. Por ejemplo, un cliente puede sentir que unos delincuentes, mucho después de que le hubieran asaltado con un arma, aún le siguen observando y van a por él. Estos clientes pueden ser incapaces de sentirse seguros en la situación actual, incluso en la consulta del terapeuta porque están convencidos de que la gente está intentando lastimarles o matarles.

Aunque no siempre es el caso, la atribución externa de las experiencias psicóticas puede evitar que el cliente desarrolle cierta distancia entre el pasado y el presente. Durante las sesiones de EMDR, los niveles de SUD será altos, independientemente de la selección de blancos, y no bajarán. La atribución externa puede funcionar como una creencia bloqueante en EMDR, impidiendo que las experiencias traumáticas sean reprocesadas. En este caso, la TCC puede ser necesaria para corregir atribuciones disfuncionales. Otras opciones son entretejidos cognitivos (EC) o desarrollo e instalación de recursos (DIR).

\section{Discapacidades cognitivas}

La falta de concentración puede ser un obstáculo. A menudo está presente como deterioro cognitivo en los trastornos psicóticos (Bora, Yucel y Pantelis, 2009). Durante el EMDR, los clientes pueden tener dificultad para seguir instrucciones y concentrarse en la imagen diana. Algunos clientes no son capaces de seguir los dedos del terapeuta (u otro estímulo distractor) con los ojos durante un tiempo relativamente largo y necesitan instrucciones repetidas para seguir haciéndolo. Las voces que les están hablando durante la sesión también distraen a algunos clientes. Preferiblemente, sin embargo, el terapeuta continuará de manera habitual. En caso de deficiencias graves, las sesiones pueden ser acortadas. Sin embargo, sólo se aconseja hacerlo cuando sea absolutamente necesario.

Algunos clientes con psicosis tienen mala memoria de trabajo (Bora et al., 2009). Se supone que la memoria de trabajo desempeña un papel central en la fase de desensibilización de EMDR (Andrade, Kavanagh y Baddeley, 1997; Gunter y Bodner, 2008). Se ha encontrado que la viveza y la emocionalidad de las imágenes traumáticas disminuyen después de hacer que la memoria de trabajo se esfuerce (Van den Hout et al., 2010). Muy poca distracción no funciona porque el cliente puede perderse en sus propios flashbacks, pero demasiada distracción puede evitar completamente que el cliente piense en los recuerdos. Un esfuerzo óptimo de la memoria de trabajo parece ser la mejor opción (Gunter y Bodner, 2008). Algunos clientes con psicosis pueden beneficiarse de una tarea exigente de la memoria de trabajo que no suponga demasiado esfuerzo; es decir, que no agote excesivamente su memoria de trabajo. Por otro lado, las imágenes traumáticas muy intrusivas requieren una fuerte distracción para que el cliente que no se sienta abrumado. Por lo tanto, va a ser necesaria una puesta a punto individualizada.

\section{Dificultad con los movimientos oculares}

Algunas personas con esquizofrenia tienen problemas con los movimientos oculares sacádicos (Krebs et al., 2010). Éstos son movimientos direccionales sobre un ángulo amplio, a menudo con los ojos siguiendo 
un estímulo. Para las personas con psicosis, los movimientos oculares sacádicos pueden ser más lentos $\mathrm{o}$, a veces, pueden estar alterados por movimientos involuntarios. Los movimientos oculares sacádicos deteriorados pueden reflejar deficiencias generales en los procesos sensorio-motores en la corteza frontal (Lee y Williams, 2000; Reilly, Lencer, Bishop, Keedy y Sweeney, 2008). En concreto, los movimientos sacádicos deteriorados pueden estar conectados con deficiencias pre-frontales en la inhibición motora (Krebs et al., 2010).

Se desconoce si estas alteraciones son un obstáculo para el EMDR. Obviamente, pueden causar algunas dificultades con el seguimiento de los ojos de un estímulo distractor. Pero estudios recientes sugieren que el mecanismo de trabajo del EMDR está basado principalmente en el esfuerzo de la memoria de trabajo mientras se piensa en imágenes traumáticas (Van den Hout et al., 2010), y esto probablemente no quede obstruido por las deficiencias sacádicas. Si es necesario, pueden ser útiles otras tareas de memoria de trabajo en lugar de los movimientos oculares, por ejemplo, tonos auditivos bilaterales, cálculos mentales, dibujar algo, juegos, dar un paseo y objetos para hacer tapping.

\section{Medicación antipsicótica}

Algunos investigadores han llegado a la conclusión de que el EMDR puede que funcione porque activa el sistema colinérgico en el cerebro (Elofsson, von Scheele, Theorell y Söndergaard, 2008). Este sistema está asociado con el aprendizaje, la memoria y la atención. Sin embargo, la medicación antipsicótica a veces bloquea los receptores colinérgicos, con efectos secundarios tales como sequedad de boca, estreñimiento, aumento de la frecuencia cardiaca, dilatación de la pupila e inquietud. Algunos clientes toman un agente anticolinérgico específico recetado como remedio para los efectos secundarios motores de los antipsicóticos (por ejemplo, benztropina o trihexifenidilo). Mientras toman este tipo de medicamentos, puede que el EMDR sea menos eficaz, al ser incapaz de activar el sistema colinérgico. Sin embargo, esto todavía no se sabe con certeza; pero puede ser útil tener en cuenta dichas interacciones cuando el EMDR no funcione y el cliente esté muy medicado. Reducir la dosis de anticolinérgicos puede ser útil.

\section{Baja expresión afectiva}

La apatía, la anhedonia y el aplanamiento afectivo son algunos de los síntomas negativos en los trastornos psicóticos. Las investigaciones indican que el aplanamiento afectivo consiste principalmente en una expresión emocional disminuida, no una ausencia de experiencia emocional subjetiva (Foussias y Remington, 2010; Myin-Germeys, Delespaul y De Vries, 2000). Esto, sin embargo, puede hacer que sea difícil saber cómo se siente el cliente durante el EMDR. A veces, un cliente indica un SUD alto, mientras que al mismo tiempo, su expresión facial no muestra signo alguno de malestar. Esto hace que sea más difícil ayudar a que el cliente se mantenga dentro de la "zona óptima de activación" o "ventana de tolerancia" (Ogden y Pain, 2006). Se aconseja hablar de esto de antemano: ¿qué tipo de puntuaciones SUD indican qué tipo de experiencia para el cliente? El terapeuta puede no verlo en el exterior, pero el cliente puede experimentar por dentro emociones muy intensas. Por lo general, no suele haber problema para hablar de esto.

\section{Efectos secundarios inusuales y desestabilización}

A veces se producen reacciones inusuales. Los autores se han encontrado con clientes que siguen escuchando los pitidos de los estímulos distractores bilaterales auditivos durante algunos días después de una sesión de EMDR. Estos efectos hasta ahora siempre han vuelto a desaparecer en un par de días.

Los síntomas psicóticos pueden aumentar temporalmente durante el EMDR (por ejemplo, la frecuencia o intensidad de las voces puede aumentar unos días). Aconsejamos mencionar esta posibilidad con antelación para que el cliente se sienta menos alarmado cuando esto suceda. En todos los años que los autores de este artículo han estado utilizando EMDR en psicosis (en pacientes ambulatorios y hospitalizados), no se han producido crisis psicóticas completas. Sin embargo, no se puede excluir esta posibilidad en el futuro. Sería importante contar con un buen plan para señalar un incremento de la psicosis y mantener contacto estrecho con colegas y la red social del cliente.

Pueden ocurrir síntomas de disociación durante el EMDR. Los autores consideran la disociación como un mecanismo disfuncional de afrontamiento para altos niveles de estrés. En el caso de reacciones disociativas, es importante que el terapeuta se mantenga calmado y presente. La mayoría de los clientes son capaces de escuchar al terapeuta. Podemos decir algo como "aparentemente el estrés ha subido demasiado. Simplemente esperaremos hasta que el estrés sea manejable de nuevo". Puede ser útil hacer que el cliente se enfoque en detalles del entorno. También puede ser útil comentar estrategias de antemano, como un toque en el hombro o nombrar 10 cosas azules en la 
habitación. Los propios clientes a menudo saben qué estrategia es eficaz para ellos. La disociación en sí es inofensiva y nuestra experiencia es que siempre se pasa.

\section{Discusión}

En este artículo, hemos ofrecido unas pautas para la conceptualización y el uso de EMDR. Los ejemplos ilustrativos de casos muestran que los trastornos psicóticos son generalmente complejos. Lo componen factores biológicos, psicológicos y sociales, y casi siempre hay comorbilidad (Buckley et al., 2009). Por tanto, los autores abogan por la integración de EMDR dentro de un tratamiento psicológico más amplio. En la práctica clínica, combinamos EMDR con TCC. Para una descripción más detallada de la TCC con psicosis, los autores hacen referencia a uno de los muchos protocolos (por ejemplo, Morrison, Renton, Dunn, Williams y Bentall, 2004). La práctica clínica muestra que el EMDR y la TCC pueden combinarse muy bien. Muy a menudo, se hace necesario un desafío cognitivo para crear un contexto en el que el EMDR tenga una buena oportunidad de funcionar con éxito. Y con muchos clientes necesitaremos hacer tareas de exposición o experimentos conductuales después del EMDR para que se den cuenta de las mejoras. Es importante señalar que en la TCC para la psicosis, los efectos del tratamiento son mayores cuando se cumplen al completo los programas de tratamiento (Dunn et al., 2012). Los autores creen que ofrecer una combinación de EMDR y TCC tiene un efecto sinérgico. Es necesario realizar investigaciones en este campo.

Cuando se trabaja con EMDR en la psicosis, es fundamental estar familiarizado con el fenómeno de la psicosis y las estrategias de tratamiento pertinentes. Las psicosis son a menudo complejas y por lo general están acompañadas de trastornos comórbidos. Por otro lado, los terapeutas que tienen experiencia en trabajar con psicosis saben que no tienen que ser excesivamente cuidadosos y que los clientes pueden manejar mucho más de lo que generalmente suponen los terapeutas que no están familiarizados con dicho trastorno. Hacemos hincapié en que no hay evidencia científica de que la psicoterapia para la psicosis sea perjudicial. En nuestra experiencia, la mayoría de las dificultades al trabajar con EMDR en la psicosis se producen en presencia de trastornos de la personalidad comórbidos en los que la inestabilidad emocional es un síntoma clave. Esto puede, por ejemplo, aumentar las posibilidades de disociación. Los autores por lo general no utilizan ninguna técnica de estabilización, sin embargo, y adoptan los procedimientos estándar de EMDR. Hay que tener en cuenta que los clientes que generalmente tratamos con EMDR están diagnosticados principalmente con esquizofrenia o trastorno esquizoafectivo y que estos clientes generalmente reciben amplia asistencia social y medicación antipsicótica. En otras palabras, a menudo ya se han implemento bastantes intervenciones de estabilización. Desafortunadamente, no existen datos que muestren indicaciones y condiciones claras para el EMDR. En este momento, cada terapeuta ha de juzgar lo que se puede y no se puede hacer en base a su experiencia clínica. Por supuesto, los clínicos deben estar atentos a los factores que influyen en la capacidad de los clientes para someterse a EMDR. Cuando existan contraindicaciones claras, debe posponerse el tratamiento o adoptar una estrategia de tratamiento diferente. Sin embargo, los autores señalan que estos factores no son diferentes en clientes con psicosis que en cualquier otro tipo de clientes. Por otra parte, se insiste en que uno de los principales problemas en la atención a las personas con psicosis es el hecho de que no se realizan intervenciones psicoterapéuticas efectivas.

\section{Referencias}

Achim, A. M., Maziade, M., Raymond, E., Olivier, D., Mérette, C., \& Roy, M. A. (2011). How prevalent are anxiety disorders in schizophrenia? A meta-analysis and critical review on a significant association. Schizophrenia Bulletin, 37(4), 811-821.

Andrade, J., Kavanagh, D., \& Baddeley, A. (1997). Eye movements and visual imagery: A working memory approach to the treatment of post-traumatic stress disorder. British Journal of Clinical Psychology, 36, 209-223.

Beck, A. T. (1970). Role of fantasies in psychotherapy and psychopathology. The Journal of Nervous and Mental Disease, 150(1), 3-17.

Bentall, R. P., Wickham, S., Shevlin, M., \& Varese, F. (2012). Do specific early-life adversities lead to specific symptoms of psychosis? A study from the 2007 the Adult Psychiatric Morbidity Survey. Schizophrenia Bulletin, 38(4), 734-740. http://dx.doi.org/10.1093/schbul/ sbs049

Blake, D. D., Weathers, F. W., Nagy, L. M., Kaloupek, D. G., Klauminzer, G., Charney, D. S., \& Keane, T. M. (1990). A clinician rating scale for assessing current and lifetime PTSD: The CAPS-1. Behavior Therapist, 13(8), 187-188.

Bora, E., Yucel, M., \& Pantelis, C. (2009). Cognitive functioning in schizophrenia, schizoaffective disorder and affective psychoses: Meta-analytic study. The British Journal of Psychiatry: The Journal of Mental Science, 195(6), 475-482. http: / / dx.doi.org/10.1192/bjp. bp.108.055731

Buckley, P. F., Miller, B. J., Lehrer, D. S., \& Castle, D. J. (2009). Psychiatric comorbidities and schizophrenia. Schizophrenia Bulletin, 35(2), 383-402. http://dx.doi. org/10.1093/schbul/sbn135 
Callcott, P., Standart, S., \& Turkington, D. (2004). Trauma within psychosis: Using a CBT model for PTSD in psychosis. Behavioural and Cognitive Psychotherapy, 32(2), 239-244.

De Bont, P. A., Van den Berg, D. P., Van der Vleugel, B. M., de Roos, C., Mulder, C. L., Becker, E. S., . . . Van Minnen, A. (2013). A multi-site single blind clinical study to compare the effects of prolonged exposure, eye movement desensitization and reprocessing and waiting list on patients with a current diagnosis of psychosis and co-morbid post traumatic stress disorder: Study protocol for the randomized controlled trial treating trauma in psychosis. Trials, 14, 151. http://dx.doi .org/10.1186/1745-6215-14-151

De Bont, P. A., Van Minnen, A., \& De Jongh, A. (2013). Treating PTSD in patients with psychosis: A withingroup controlled feasibility study examining the efficacy and safety of evidence-based PE and EMDR protocols. Behavior Therapy, 44(4), 717-730. http://dx.doi.org/10 $.1016 /$ j.beth .2013 .07 .00

De Jongh, A., \& Ten Broeke, E. (2007). Treatment of specific phobias with EMDR: Conceptualization and strategies for the selection of appropriate memories. Journal of EMDR Practice and Research, 1(1), 46-56. http: / / dx.doi .org/10.1891/1933-3196.1.1.46

De Jongh, A., Ten Broeke, E., \& Meijer, S. (2010). Two method approach: A case conceptualization model in the context of EMDR. Journal of EMDR Practice and Research, 4(1), 12-21. http: / / dx.doi .org/10.1891/1933-3196.4.1.12

Dunn, G., Fowler, D., Rollinson, R., Freeman, D., Kuipers, E., Smith, B., .. Bebbington, P. (2012). Effective elements of cognitive behaviour therapy for psychosis: Results of a novel type of subgroup analysis based on principal stratification. Psychological Medicine, 42(5), 1057-1068. http: / / dx.doi.org/10.1017/S0033291711001954

Elofsson, U. O., von Schèele, B., Theorell, T., \& Söndergaard, H. P. (2008). Physiological correlates of eye movement desensitization and reprocessing. Journal of Anxiety Disorders, 22(4), 622-634. http://dx.doi. org/10.1016/j .janxdis.2007.05.012

Engelhard, I. M., Van den Hout, M. A., Dek, E. C., Giele, C. L., Van der Wielen, J. W., Reijnen, M. J., \& Van Roij, B. (2011). Reducing vividness and emotional intensity of recurrent "flashforwards" by taxing working memory: An analogue study. Journal of Anxiety Disorders, 25(4), 599 -603. http: / / dx.doi.org/10.1016/j.janxdis.2011.01.009

Engelhard, I. M., Van den Hout, M. A., Janssen, W. C., \& Van der Beek, J. (2010). Eye movements reduce vividness and emotionality of "flash-forwards." Behaviour Research and Therapy, 48(5), 442-447. http://dx.doi. org/10.1016/j .brat.2010.01.003

Fisher, H. L., Schreier, A., Zammit, S., Maughan, B., Munafò, M. R., Lewis, G., \& Wolke, D. (2012). Pathways between childhood victimization and psychosis-like symptoms in the ALSPAC birth cohort. Schizophrenia Bulletin, 39, 10451055. http: / / dx.doi.org/10.1093/schbul/sbs08

Foussias, G., \& Remington, G. (2010). Negative symptoms in schizophrenia: Avolition and Occam's razor.
Schizophrenia Bulletin, 36(2), 359-369. http://dx.doi .org/10.1093/schbul/sbn094

Fowler, D. G., Freeman, D., Steel, C., Hardy, A., Smith, B. H., Hackmann, C., . . . Bennington, P. E. (2006). The catastrophic interaction hypothesis: How do stress, trauma, emotion and information processing abnormalities lead to psychosis? In W. Larkin \& A. P. Morrison (Eds.), Trauma and psychosis (pp. 101-124). Chichester, United Kingdom: John Wiley and Sons.

Frueh, C. B., Grubaugh, A. L., Cusack, K. J., Kimble, M. O., Elhai, J. D., \& Knapp, R. G. (2009). Exposure-based cognitive-behavioral treatment of PTSD in adults with schizophrenia or schizoaffective disorder: A pilot study. Journal of Anxiety Disorders, 23(5), 665-675. http: / / dx.doi.org/10.1016/j.janxdis.2009.02.005

Garety, P. A., Kuipers, E., Fowler, D., Freeman, D., \& Bebbington, P. E. (2001). A cognitive model of the positive symptoms of psychosis. Psychological Medicine, 31(2), 189-195.

Gracie, A., Freeman, D., Green, S., Garety, P. A., Kuipers, E., Hardy, A., . . Fowler, D. (2007). The association between traumatic experience, paranoia and hallucinations: A test of the pre- dictions of psychological models. Acta Psychiatrica Scandinavica, 116(4), 280-289. http:// dx.doi. org/10.1111/j.1600-0447.2007.01011.x

Grubaugh, A. L., Tuerk, P. W., Egede, L. E., \& Frueh, B. C. (2012). Perceptions of PTSD research participation among patients with severe mental illness. Psychiatry Research, 200(2-3), 1071-1073. http:/ / dx.doi.org/10.1016/ j.psychres.2012.07.039

Gunter, R. W., \& Bodner, G. E. (2008). How eye movements affect unpleasant memories: Support for a workingmemory account. Behaviour Research and Therapy, 46(8), 913-931. http: / / dx.doi.org/10.1016/j. brat.2008.04.006

Hackmann, A., Surawy, C., \& Clark, D. M. (1998). Seeing yourself through others' eyes: A study of spontaneously occurring images in social phobia. Behavioural and Cognitive Psychotherapy, 26(1), 3-12.

Hardy, A., Fowler, D., Freeman, D., Smith, B., Steel, C., Evans, J., . . Dunn, G. (2005). Trauma and hallucinatory experience in psychosis. The Journal of Nervous and Mental Disease, 193(8), 501-507. http://dx.doi.org/10.1097/01 .nmd.0000172480.56308.21

Kim, D., Choi, J., Kim, S. H., Oh, D. H., Park, S. C., \& Lee, S. H. (2010). A pilot study of brief eye movement desensitization and reprocessing (EMDR) for treatment of acute phase schizophrenia. Korean Journal of Biological Psychiatry, 17(2), 94-102.

Krebs, M. O., Bourdel, M. C., Cherif, Z. R., Bouhours, P., Lôo, H., Poirier, M. F., \& Amado, I. (2010). Deficit of inhibition motor control in untreated patients with schizophrenia: Further support from visually guided saccade paradigms. Psychiatry Research, 179(3), 279-284. http: / / dx.doi.org/10.1016/j.psychres.2009.07.008

Lee, K. H., \& Williams, L. M. (2000). Eye movement dysfunction as a biological marker of risk for schizophrenia. Australian and New Zealand Journal of Psychiatry, 34(Suppl.), S91-S100. 
Lockett, S. H., Hatton, J., Turner, R., Stubbins, C., Hodgekins, J., \& Fowler, D. (2012). Using a semi- structured interview to explore imagery experienced during social anxiety for clients with a diagnosis of psychosis: An exploratory study conducted within an early intervention for psychosis service. Behavioural and Cognitive Psychotherapy, 40(1), 55-68. http:/ / dx.doi. org/10.1017/ S1352465811000439

Journal of EMDR Practice and Research, Volume 7, Number 4, 2013 EMDR in Psychosis

Logie, R., \& De Jongh, A. (in press). The 'Flashforward procedure': Confronting the catastrophe. Manuscript submitted for publication.

Lothian, J., \& Read, J. (2002). Asking about abuse during mental health assessments: Clients' views and experiences. New Zealand Journal of Psychology, 31(2), 98-103.

Matheson, S. L., Shepherd, A. M., Pinchbeck, R. M., Laurens, K. R., \& Carr, V. J. (2013). Childhood adversity in schizophrenia: A systematic meta-analysis. Psychological Medicine, 43(2), 225-238. http:/ / dx.doi.org/10.1017/ S0033291712000785

Morrison, A. P. (2004). The use of imagery in cognitive therapy for psychosis: A case example. Memory (Hove, England), 12(4), 517-524. http://dx.doi.org/10 $.1080 / 09658210444000142$

Morrison, A. P., Beck, A. T., Glentworth, D., Dunn, H., Reid, G. S., Larkin, W., \& Williams, S. (2002). Imagery and psychotic symptoms: A preliminary investigation. Behaviour Research and Therapy, 40(9), 1053-1062.

Morrison, A. P., Frame, L., \& Larkin, W. (2003). Relationships between trauma and psychosis: A review and integration. The British Journal of Clinical Psychology/The British Psychological Society, 42(Pt. 4), 331-353.

Morrison, A. P., Renton, J. C., Dunn, H., Williams, S., \& Bentall, R. P. (2004). Cognitive therapy for psychosis: A formulation-based approach. New York, NY: Brunner-Routledge.

Mueser, K. T., Rosenberg, S. D., Goodman, L. A., \& Trumbetta, S. L. (2002). Trauma, PTSD, and the course of severe mental illness: An interactive model. Schizophrenia Research, 53, 123-143.

Mueser, K. T., Rosenberg, S. D., Xie, H., Jankowski, M. K., Bolton, E. E., Lu, W., . . . Wolfe, R. (2008). A randomized controlled trial of cognitive-behavioral treatment for posttraumatic stress disorder in severe mental illness. Journal of Consulting and Clinical Psychology, 76(2), 259271. http: / / dx.doi.org/10.1037/0022-006X.76.2.259

Myin-Germeys, I., Delespaul, P. A., \& De Vries, M. W. (2000). Schizophrenia patients are more emotionally active than is assumed based on their behavior. Schizophrenia Bulletin, 26(4), 847-854.

Ogden, P. K. M., \& Pain, C. (2006). Trauma and the body. New York, NY: W. W. Norton \& Company.

Paulik, G. (2012). The role of social schema in the experience of auditory hallucinations: A systematic review and a proposal for the inclusion of social schema in a cognitive behavioural model of voice hearing. Clinical Psychology \& Psychotherapy, 19(6), 459-472.

Read, J., Hammersley, P., \& Rudegeair, T. (2007). Why, when and how to ask about childhood abuse. Advances in Psychiatric Treatment, 13(2), 101-110. http://dx.doi .org/10.1192/apt.bp.106.002840

Read, J., Van Os, J., Morrison, A. P., \& Ross, C. A. (2005). Childhood trauma, psychosis and schizophrenia: A literature review with theoretical and clinical implications. Acta Psychiatrica Scandinavica, 112(5), 330-350. http:// dx.doi.org/10.1111/j.1600-0447.2005.00634.x

Reilly, J. L., Lencer, R., Bishop, J. R., Keedy, S., \& Sweeney, J. A. (2008). Pharmacological treatment effects on eye movement control. Brain and Cognition, 68(3), 415-435. http: / / dx.doi.org/10.1016/j.bandc.2008.08.026

Schulze, K., Freeman, D., Green, C., \& Kuipers, E. (2013). Intrusive mental imagery in patients with persecutory delusions. Behaviour Research and Therapy, 51(1), 7-14. http: / / dx.doi.org/10.1016/j.brat.2012.10.002

Shapiro, F. (1995). Eye movement desensitization and reprocessing: Basic principles, protocols, and procedures. New York, NY: Guilford Press.

Shapiro, F. (2001). Eye movement desensitization and reprocessing: Basic principles, protocols, and procedures (2nd ed.). New York, NY: Guilford Press.

Spinazzola, J., Blaustein, M., \& Van der Kolk, B. A. (2005). Posttraumatic stress disorder treatment outcome research: The study of unrepresentative samples? Journal of Traumatic Stress, 18(5), 425-436. http://dx.doi .org/10.1002/jts.20050

Van den Berg, D. P. G., \& Van der Gaag, M. (2012). Treating trauma in psychosis with EMDR: A pilot study. Journal of Behavior Therapy and Experimental Psychiatry,43(1), 664-671. http: / / dx.doi.org/10.1016/j.jbtep.2011.09.011

Van den Hout, M. A., Engelhard, I. M., Smeets, M. A. M., Hornsveld, H., Hoogeveen, E., de Heer, E., \& Rijkeboer, M. (2010). Counting during recall: Taxing of working memory and reduced vividness and emotionality of negative memories. Applied Cognitive Psychology, 24(3), 303-311. http: / / dx.doi.org/10.1002/acp.1677

Varese, F., Smeets, F., Drukker, M., Lieverse, R., Lataster, T., Viechtbauer, W., . . Bentall, R. P. (2012). Childhood adversities increase the risk of psychosis: A meta-analysis of patient-control, prospective- and cross-sectional cohort studies. Schizophrenia Bulletin, 38(4), 661-671. http: / / dx.doi.org/10.1093/schbul/sbs050

Agradecimientos. Los autores agradecen la orientación editorial de Daeho Kim en la preparación de este artículo.

La correspondencia relacionada con este artículo debe dirigirse a David P.G. Van den Berg, Parnassia Psychiatric Institute, Zoutkeetsingel 40, 2512 HN, Den Haag, Holanda. E-mail: d.vandenberg@parnassia.nl 